\title{
Expression of Myxovirus Resistance A (MxA) Is Associated with Tumor-Infiltrating Lymphocytes in Human Epidermal Growth Factor Receptor 2 (HER2)-Positive Breast Cancers
}

\section{So Jeong Lee, $\mathrm{MD}^{1}$ \\ Cheong-Soo Hwang, MD ${ }^{1}$ \\ Young-Keum Kim, MD \\ Hyun Jung Lee, $M D^{2}$ \\ Sang-Jeong Ahn, MD \\ Nari Shin, MD² \\ Jung Hee Lee, MD, PhD² \\ Dong Hoon Shin, MD, PhD² \\ Kyung Un Choi, MD, PhD \\ Do Youn Park, MD, PhD' \\ Chang Hun Lee, MD, PhD' \\ Gi Young Huh, MD, PhD ${ }^{1}$ \\ Mi Young Sol, MD, PhD² \\ Hee Jin Lee, MD, PhD ${ }^{3}$ \\ Gyungyub Gong, $\mathrm{MD}, \mathrm{PhD}^{3}$ \\ Jee Yeon Kim, MD, PhD² \\ Ahrong Kim, MD ${ }^{1}$}

\section{${ }^{1}$ Department of Pathology, BioMedical Research Institute, Pusan National University Hospital, Busan, ${ }^{2}$ Department of Pathology, Pusan National University Yangsan Hospital, Yangsan, ${ }^{3}$ Department of Pathology, Asan Medical Center, University of Ulsan College of Medicine, Seoul, Korea}

\section{Purpose}

The prognostic significance of tumor-infiltrating lymphocytes (TILS) has been determined in breast cancers. Interferons can affect T-cell activity through direct and indirect mechanisms. Myxovirus resistance $\mathrm{A}(\mathrm{MxA})$ is an excellent marker of interferon activity. Here, we evaluated TILs and MxA expression in human epidermal growth factor receptor 2 (HER2)-positive breast cancers.

\section{Materials and Methods}

Ninety cases of hormone receptor (HR)+/HER2+ tumors and 78 cases of HR-/HER2+ tumors were included. The TILs level was assessed using hematoxylin and eosin-stained full face sections, and MxA expression was evaluated by immunohistochemistry with a tissue microarray.

\section{Results}

MxA protein expression was significantly higher in tumors with high histologic grade $(p=0.023)$ and high levels of TILs ( $p=0.002)$. High levels of TILs were correlated with high histological grade $(p=0.001)$, negative lymphovascular invasion $(p=0.007)$, negative lymph node metastasis ( $p=0.007)$, absence of HR expression $(p<0.001)$, abundant tertiary lymphoid structures (TLSs) around ductal carcinoma in situ $(p=0.018)$, and abundant TLSs around the invasive component $(p<0.001)$. High levels of TILs were also associated with improved disease-free survival, particularly in HR-/HER2+ breast cancers. However, MxA was not a prognostic factor.

\section{Conclusion}

High expression of MxA in tumor cells was associated with high levels of TILs in HER2-positive breast cancers. Additionally, a high level of TILs was a prognostic factor for breast cancer, whereas the level of MxA expression had no prognostic value. $\begin{array}{ll}\text { Correspondence: Jee Yeon Kim, MD, PhD } & \text { Key words } \\ \text { Department of Pathology, Pusan National } & \text { Tumor-infiltrating lymphocytes, Myxovirus resistance proteins, } \\ \text { University Yangsan Hospital, 20 Geumo-ro, } & \text { Breast neoplasms }\end{array}$

$\begin{array}{ll}\text { Correspondence: Jee Yeon Kim, MD, PhD } & \text { Key words } \\ \text { Department of Pathology, Pusan National } & \text { Tumor-infiltrating lymphocytes, Myxovirus resistance proteins, } \\ \text { University Yangsan Hospital, 20 Geumo-ro, } & \text { Breast neoplasms }\end{array}$

$\begin{array}{ll}\text { Correspondence: Jee Yeon Kim, MD, PhD } & \text { Key words } \\ \text { Department of Pathology, Pusan National } & \text { Tumor-infiltrating lymphocytes, Myxovirus resistance proteins, } \\ \text { University Yangsan Hospital, 20 Geumo-ro, } & \text { Breast neoplasms }\end{array}$

Tel: 82-55-360-1859

Fax: 82-55-360-1865

E-mail: artinus2000@naver.com

Co-correspondence: Ahrong Kim, MD

Department of Pathology, BioMedical Research

Institute, Pusan National University Hospital,

179 Gudeok-ro, Seo-gu, Busan 49241, Korea

Tel: 82-51-240-7422

Fax: 82-52-256-0788

E-mail: ahrong2h@naver.com

Received March 8, 2016

Accepted June 16, 2016

Published Online July 7, 2016 


\section{Introduction}

Progress in immunotherapy has provided novel insights into the roles of tumor-infiltrating lymphocytes (TILs) in cancer. The prognostic significance of TILs has been determined in breast cancers, particularly human epidermal growth factor receptor 2 (HER2)-positive breast cancers and triple-negative breast cancers [1]. The prognosis of HER2-positive breast cancer has dramatically improved because of introduction of trastuzumab, a humanized monoclonal antibody targeting the extracellular domain of HER2. Immune-mediated mechanisms may play a role in treatment with trastuzumab [2]. In the adjuvant setting, a high level of TILs is associated with better response to trastuzumab, and an abundant number of TILs is an independent prognostic factor in HER2-positive breast cancer [3]. Based on this background, a group of investigators around the world convened to discuss the parameters and methodological issues associated with evaluating TILs in breast cancers [4] and released recommendations for their evaluation. They recommended that all mononuclear cells, including lymphocytes and plasma cells in intratumoral stroma, be scored as a percentage of the area occupied over the total intratumoral stromal area.

The innate immune system lies at the frontline of the cellular response to pathogen infection. Pattern recognition receptors sense microbial products, including RNA produced during viral infection [5], and interferon (IFN) expression is then upregulated, resulting in stimulation of the transcription of various IFN-stimulated genes (ISGs), including the myxovirus resistance $\mathrm{A}(\mathrm{MxA})$ gene, through phosphorylation of signal transducer and activator of transcription 1 (STAT1). In addition to its function in innate immunity, ISGs are known to be broadly expressed in various types of tumors [6], and IFNs are known to participate in receptor-activated signaling pathways associated with the pathophysiology of malignancies [7]. Additionally, some studies have shown that MxA may have a tumor-suppressive function [8]. Expression of the MxA gene is regulated by IFNs, but not by other cytokines. Moreover, MxA gene expression is not induced directly by viral infection, but is dependent on IFN signaling, making MxA an excellent marker for IFN action [9]. Activation of the IFN pathway is a common outcome of damage-associated molecular pattern (DAMP) signaling [10]. A recent report demonstrated that high cytoplasmic expression of high mobility group (HMG) B1 and HMGN1, which are DAMPs associated with innate immunity in the extracellular environment, is associated with a high level of TILs in HER2-positive breast cancers [11]. We hypothesized that MxA, an effective marker of IFN signaling that is an important component of innate immunity, may play a role in TILs in HER2-positive breast cancers.

In this study, we analyzed the expression of MxA protein in HER2-positive breast cancers and the relationship between the expression level of MxA and various histopathologic variables, including TIL levels.

\section{Materials and Methods}

\section{Patient and tissue specimens}

A total of 168 patients with HER2-positive breast cancer who underwent surgery for primary breast cancer between 2011 and 2013 at Pusan National University Hospital were included. Formalin-fixed, paraffin-embedded tissue samples were available for all cases. Clinicopathologic information was based on the patients' medical records and pathologic reports. All patients were preoperatively chemotherapy and radiotherapy naïve and treated with trastuzumab.
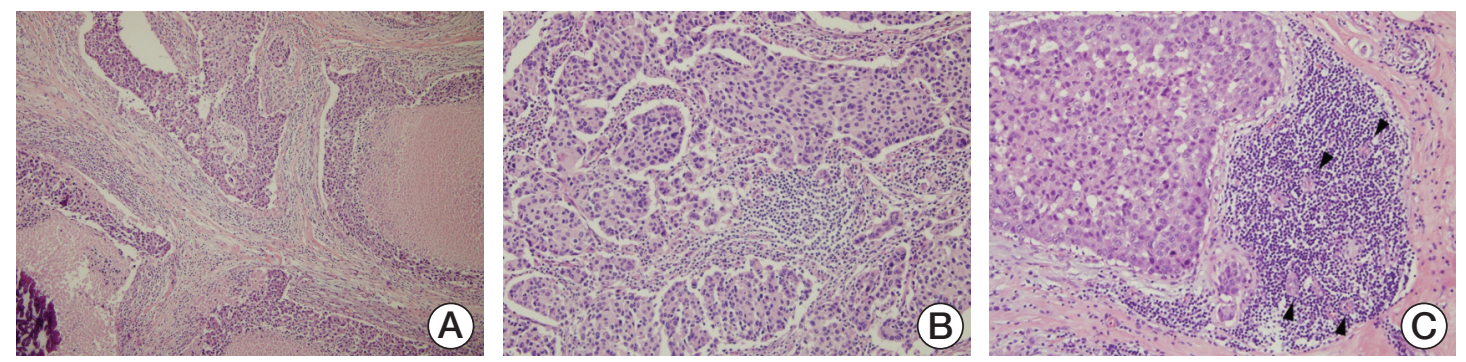

Fig. 1. Evaluation of tumor infiltrating lymphocytes (TILs) level by histology with hematoxylin and eosin-stained sections according to the recommendation by the International TILs Working Group and tertiary lymphoid structures. Interpreted as $50 \%(\mathrm{~A}, \times 100)$ and $70 \%(\mathrm{~B}, \times 200)$ of TILs and tertiary lymphoid structure $(\mathrm{C}, \times 200)$, a lymph-node like lymphoid accumulation showing high endothelial venule (arrowheads). 

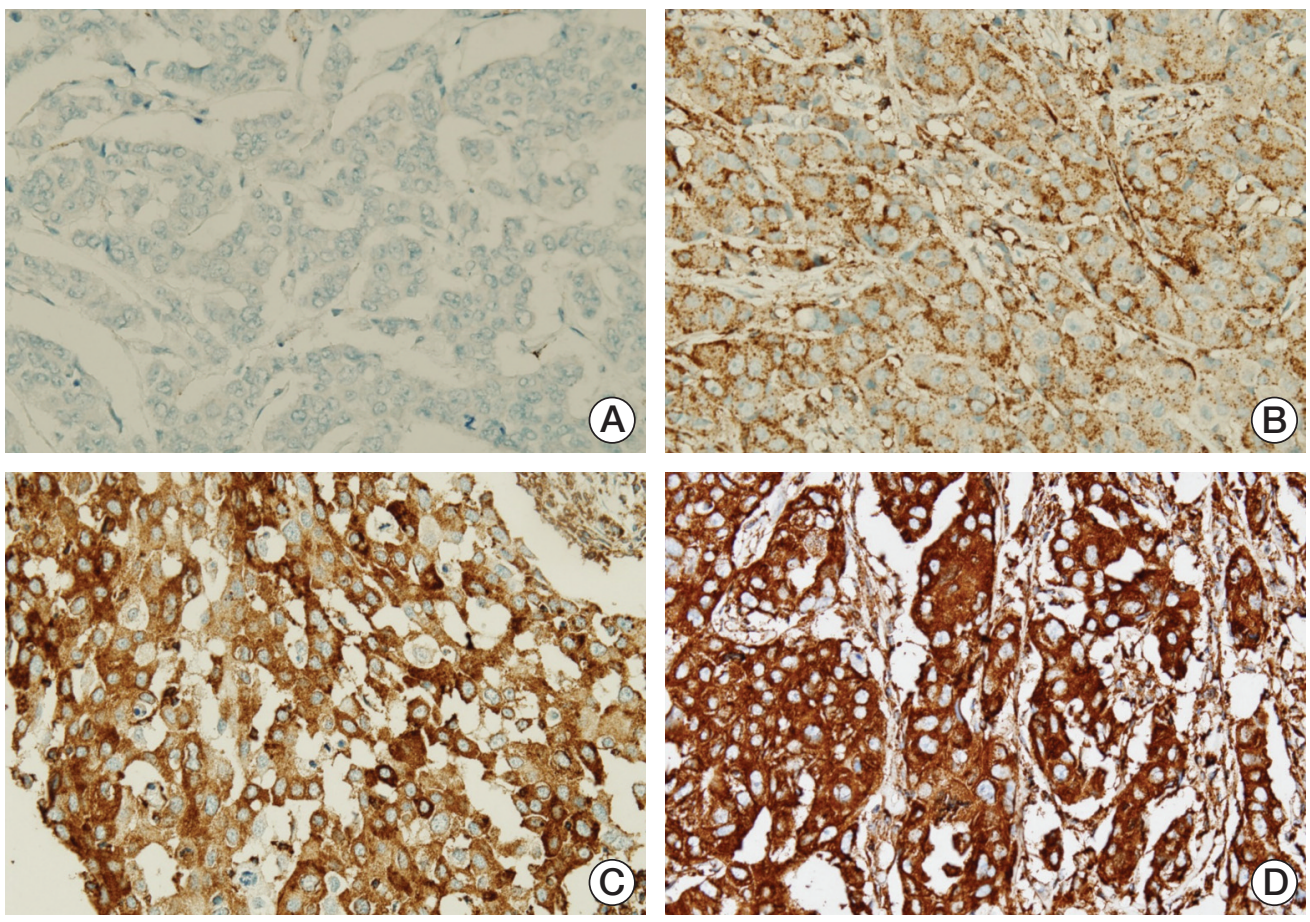

Fig. 2. Expression of myxovirus resistance $A(M x A)$ by immunohistochemistry: negative staining $(A, \times 400)$, weak staining $(B, \times 400)$, moderate staining $(C, \times 400)$, and strong staining $(D, \times 400)$ for $M x A$.

Expression statuses of estrogen receptor (ER), progesterone receptor (PR), and HER2 were evaluated for all samples, and immunohistochemistry for these proteins was performed at the time of diagnosis. Exemption from informed consent after de-identification of the patients' information was approved by the Institutional Review Board of Pusan National University Hospital.

\section{Histologic evaluation}

Hematoxylin and eosin (H\&E)-stained slides were reviewed by two pathologists (A.K. and J.Y.K.). Histopathologic factors included histologic grade, nuclear grade, necrosis, microcalcification, lymphovascular invasion, lymph node metastasis, TILs level, tertiary lymphoid structures (TLSs) around the ductal carcinoma in situ (DCIS), and TLS around the invasive component. Histologic grade and nuclear grade were assessed by the modified Bloom-Richardson classification. TILs levels were evaluated based on the recommendation by the International TILs Working Group, and TILs level was calculated according to the percentage of stroma in the invasive area (Fig. 1A and B) [4]. TLS is a lymph-node like structure characterized by ectopic aggregation of lymphoid cells with specialized high endothelial venules. Lymphoid accumulation containing vessels with high endothelial venule features (plump and cuboidal endothelial cells) was considered to be the TLS (Fig. 1C) [3]. We evaluated the ducts involved by DCIS with surrounding TLSs as a percentage of total ducts involved by DCIS and the amount of TLSs as a percentage of the total circumference of the invasive edge. To conduct statistical analysis, the TILs levels were subdivided into three categories $(\leq 10 \%, 20 \%-60 \%$, and $>60 \%)$ or two categories $(\leq 60 \%$ and $>60 \%)$, as appropriate. The level of TLS abundance was divided into two subgroups (low and high) based on the mean value.

\section{Construction of tissue microarray blocks and immuno- histochemical evaluation}

To define the representative tumor area, all H\&E-stained slides were reviewed. Each sample was arrayed with a tissue cylinder $2 \mathrm{~mm}$ in diameter using a tissue arraying instrument. To minimize tissue loss and the effects of tumor heterogeneity, all samples were arrayed in duplicate.

Tissue sections were stained with an automated immunohistochemical staining device (Benchmark XT, Ventana Medical Systems, Tucson, AZ). Briefly, 3- $\mu$ m-thick paraffin sections were deparaffinized in EZ prep using an autostainer. For antigen retrieval, cell conditioner $1(\mathrm{pH} 8.4$ buffer) or cell conditioner 2 ( $\mathrm{pH} 6.0$ buffer) was used. Opti- 
mally formulated antibodies targeting ER (1:200, Leica Biosystems, Newcastle upon Tyne, UK), PR (1:200, Leica Biosystems), and HER-2/ neu (1:8, Ventana Medical Systems) were used, and an anti-MxA antibody (1:1,000, ab95926, Abcam, Cambridge, UK) was also applied. A HER2/CEP17 chromosome dual-probe (Ventana Medical Systems) was used for silver in situ hybridization (SISH).

ER and PR positivity were defined as at least $1 \%$ positive staining in tumor nuclei. Tumors that were positive for ER or PR were categorized as the hormone receptor (HR)-posi- tive group. HER2 positivity was defined as an immunohistochemical staining score of 3 or gene amplification as identified by SISH. SISH was performed in cases of equivocal immunostaining with a score of 2 . Tumors were classified into the following two subtypes according to HR (ER and PR) expression status: HR+/HER2+ and HR-/HER2+.

The intensity of the staining and percentage of positive tumor cells were considered together for MxA. The intensity of the immunohistochemistry was graded as 0 (negative), 1 (weak), 2 (moderate), and 3 strong (Fig. 2), after which the

Table 1. Correlations of clinicopathological factors with HR expression status in HER2-positive breast cancers

\begin{tabular}{|c|c|c|c|}
\hline Factor & HR-positive tumor & HR-negative tumor & p-value \\
\hline Age & $51.27 \pm 10.08$ & $54.18 \pm 9.97$ & 0.062 \\
\hline Size $(\mathrm{cm})$ & $3.05 \pm 1.43$ & $3.38 \pm 2.09$ & 0.225 \\
\hline \multicolumn{4}{|l|}{ Histologic grade } \\
\hline Low (grade 1 and 2) & $48(53.3)$ & $15(19.2)$ & $<0.001$ \\
\hline High (grade 3) & $42(46.7)$ & $63(80.8)$ & \\
\hline \multicolumn{4}{|l|}{ Nuclear grade } \\
\hline Low (grade 1 and 2) & $25(27.8)$ & $4(5.1)$ & $<0.001$ \\
\hline High (grade 3) & $65(72.2)$ & $74(94.9)$ & \\
\hline \multicolumn{4}{|l|}{ Necrosis } \\
\hline Absent & $36(40.0)$ & $22(28.2)$ & 0.143 \\
\hline Present & $54(60.0)$ & $56(71.8)$ & \\
\hline \multicolumn{4}{|l|}{ Microcalcification } \\
\hline Absent & $44(48.9)$ & $36(46.2)$ & 0.758 \\
\hline Present & $46(51.1)$ & $42(53.8)$ & \\
\hline \multicolumn{4}{|l|}{ Lymphovascular invasion } \\
\hline Absent & $50(55.6)$ & $41(52.6)$ & 0.757 \\
\hline Present & $40(44.4)$ & $37(47.4)$ & \\
\hline \multicolumn{4}{|l|}{ Lymph node metastasis } \\
\hline Absent & $44(48.9)$ & $35(44.9)$ & 0.644 \\
\hline Present & $46(51.1)$ & $43(55.1)$ & \\
\hline \multicolumn{4}{|l|}{ Stage } \\
\hline Early (stage 1 and 2) & $80(88.9)$ & $64(82.1)$ & 0.270 \\
\hline Advanced (stage 3 and 4) & $10(11.1)$ & $14(17.9)$ & \\
\hline MxA immunoscore & $88.61 \pm 84.17$ & $100.83 \pm 85.88$ & 0.354 \\
\hline \multicolumn{4}{|l|}{ TILs level $(\%)$} \\
\hline$\leq 10$ & $46(51.1)$ & $16(20.5)$ & $<0.001$ \\
\hline $20-60$ & $35(38.9)$ & $39(50.0)$ & \\
\hline$>60$ & $9(10.0)$ & $23(29.5)$ & \\
\hline \multicolumn{4}{|l|}{ TLSs around DCIS } \\
\hline Low & $59(65.6)$ & $44(56.4)$ & 0.267 \\
\hline High & $31(34.4)$ & $34(43.6)$ & \\
\hline \multicolumn{4}{|c|}{ TLSs around invasive component } \\
\hline Low & $55(61.1)$ & $55(70.5)$ & 0.255 \\
\hline High & $35(38.9)$ & $23(29.5)$ & \\
\hline
\end{tabular}

Values are presented as mean \pm standard deviation or number $(\%)$. HR, hormone receptor; HER2, human epidermal growth factor receptor 2; MxA, myxovirus resistance A; TIL, tumor infiltrating lymphocyte; TLS, tertiary lymphoid structure; DCIS, ductal carcinoma in situ. 
Table 2. Correlations of clinicopathologic factors with MxA expression levels in HER2-positive breast cancers

\begin{tabular}{|c|c|c|c|}
\hline \multirow{2}{*}{ Factor } & \multicolumn{2}{|c|}{ MxA expression } & \multirow{2}{*}{ p-value } \\
\hline & Low & High & \\
\hline Age (yr) & $52.62 \pm 10.74$ & $52.61 \pm 9.14$ & 0.994 \\
\hline Size $(\mathrm{cm})$ & $3.28 \pm 1.93$ & $3.08 \pm 1.51$ & 0.476 \\
\hline \multicolumn{4}{|l|}{ Histologic grade } \\
\hline Low (grade 1 and 2) & $45(44.6)$ & $18(26.9)$ & 0.023 \\
\hline High (grade 3) & $56(55.4)$ & $49(73.1)$ & \\
\hline \multicolumn{4}{|l|}{ Nuclear grade } \\
\hline Low (grade 1 and 2) & $22(21.8)$ & $7(10.4)$ & 0.063 \\
\hline High (grade 3) & $79(78.2)$ & $60(89.6)$ & \\
\hline \multicolumn{4}{|l|}{ Necrosis } \\
\hline Absent & $38(37.6)$ & $20(29.9)$ & 0.324 \\
\hline Present & $63(62.4)$ & $47(70.1)$ & \\
\hline \multicolumn{4}{|l|}{ Microcalcification } \\
\hline Absent & $49(48.5)$ & $31(46.3)$ & 0.875 \\
\hline Present & $52(51.5)$ & $36(53.7)$ & \\
\hline \multicolumn{4}{|l|}{ Lymphovascular invasion } \\
\hline Absent & $53(52.5)$ & $38(56.7)$ & 0.637 \\
\hline Present & $48(47.5)$ & $29(43.3)$ & \\
\hline \multicolumn{4}{|l|}{ Lymph node metastasis } \\
\hline Absent & $47(46.5)$ & $32(47.8)$ & $>0.990$ \\
\hline Present & $54(53.5)$ & $35(52.2)$ & \\
\hline \multicolumn{4}{|l|}{ Stage } \\
\hline Early (stage 1 and 2) & $86(85.1)$ & $58(86.6)$ & $>0.990$ \\
\hline Advanced (stage 3 and 4) & $15(14.9)$ & $9(13.4)$ & \\
\hline \multicolumn{4}{|l|}{ HR expression } \\
\hline Positive & $57(56.4)$ & $33(49.3)$ & 0.430 \\
\hline Negative & $44(43.6)$ & $34(50.7)$ & \\
\hline \multicolumn{4}{|l|}{ TILs level (\%) } \\
\hline$\leq 10$ & $46(45.5)$ & $16(23.9)$ & 0.002 \\
\hline $20-60$ & $43(42.6)$ & $31(46.3)$ & \\
\hline$>60$ & $12(11.9)$ & $20(29.9)$ & \\
\hline \multicolumn{4}{|l|}{ TLSs around DCIS } \\
\hline Low & $63(62.4)$ & $40(59.7)$ & 0.748 \\
\hline High & $38(37.6)$ & $27(40.3)$ & \\
\hline \multicolumn{4}{|c|}{ TLSs around invasive component } \\
\hline Low & $69(68.3)$ & $41(61.2)$ & 0.408 \\
\hline High & $32(31.7)$ & $26(38.8)$ & \\
\hline
\end{tabular}

Values are presented as mean \pm standard deviation or number (\%). MxA, myxovirus resistance A; HER2, human epidermal growth factor receptor 2; HR, hormone receptor; TILs, tumor infiltrating lymphocytes; TLS, tertiary lymphoid structure; DCIS, ductal carcinoma in situ.

percentage of positive tumor cells was evaluated. The immunoscore was generated by multiplying the staining intensity by the percentage of the positive tumor cells. Finally, we subdivided the tumors into two groups (low and high expression) according to the mean value to enable statistical analysis.

\section{Statistical analysis}

All statistical analyses were conducted using the SPSS ver. 22 (IBM Corp., Armonk, NY). Chi-square tests, linear-by-linear association tests, Fisher exact tests, and Spearman rank correlation tests were used as appropriate. All tests were two-sided, and differences with p-values of less than 0.05 were considered significant. 
Table 3. Correlation between histopathologic variables and TILs levels in HER2-positive breast cancers

\begin{tabular}{|c|c|c|c|c|}
\hline \multirow{2}{*}{ Factor } & \multicolumn{3}{|c|}{ TILs level (\%) } & \multirow{2}{*}{ p-value } \\
\hline & $\leq 10$ & $20-60$ & $>60$ & \\
\hline \multicolumn{5}{|l|}{ Histologic grade } \\
\hline Low (grade 1 and 2) & $34(54.8)$ & $23(31.1)$ & $6(18.8)$ & 0.001 \\
\hline High (grade 3) & $28(45.2)$ & $51(68.9)$ & $26(81.3)$ & \\
\hline \multicolumn{5}{|l|}{ Nuclear grade } \\
\hline Low (grade 1 and 2) & $16(25.8)$ & $11(14.9)$ & $2(6.3)$ & 0.057 \\
\hline High (grade 3) & $46(74.2)$ & $63(85.1)$ & $30(93.8)$ & \\
\hline \multicolumn{5}{|l|}{ Necrosis } \\
\hline Absent & $24(38.7)$ & $24(32.4)$ & $10(31.3)$ & 0.672 \\
\hline Present & $38(61.3)$ & $50(67.6)$ & $22(68.8)$ & \\
\hline \multicolumn{5}{|l|}{ Microcalcification } \\
\hline Absent & $23(37.1)$ & $38(51.4)$ & $19(59.4)$ & 0.086 \\
\hline Present & $39(62.9)$ & $36(48.6)$ & $13(40.6)$ & \\
\hline \multicolumn{5}{|l|}{ Lymphovascular invasion } \\
\hline Absent & $28(45.2)$ & $38(51.4)$ & $25(78.1)$ & 0.007 \\
\hline Present & $34(54.8)$ & $36(48.6)$ & $7(21.9)$ & \\
\hline \multicolumn{5}{|l|}{ Lymph node metastasis } \\
\hline Absent & $27(43.5)$ & $29(39.2)$ & $23(71.9)$ & 0.007 \\
\hline Present & $35(56.5)$ & $45(60.8)$ & $9(28.1)$ & \\
\hline \multicolumn{5}{|l|}{ Stage } \\
\hline Early (stage 1 and 2) & $55(88.7)$ & $59(79.7)$ & $30(93.8)$ & 0.132 \\
\hline Advanced (stage 3 and 4) & $7(11.3)$ & $15(20.3)$ & $2(6.3)$ & \\
\hline \multicolumn{5}{|l|}{ HR expression } \\
\hline Negative & $16(25.8)$ & $39(52.7)$ & $23(71.9)$ & $<0.001$ \\
\hline Positive & $46(74.2)$ & $35(47.3)$ & $9(28.1)$ & \\
\hline \multicolumn{5}{|l|}{ TLSs around DCIS } \\
\hline Absent & $46(74.2)$ & $42(56.8)$ & $15(46.9)$ & 0.018 \\
\hline Present & $16(25.8)$ & $32(43.2)$ & $17(53.1)$ & \\
\hline \multicolumn{5}{|c|}{ TLSs around invasive component } \\
\hline Absent & $52(83.9)$ & $41(55.4)$ & $17(53.1)$ & $<0.001$ \\
\hline Present & $10(16.1)$ & $33(44.6)$ & $15(46.9)$ & \\
\hline
\end{tabular}

TIL, tumor infiltrating lymphocyte; HER2, human epidermal growth factor receptor 2; HR, hormone receptor; TLS, tertiary lymphoid structures; DCIS, ductal carcinoma in situ.

\section{Results}

\section{Clinicopathological characteristics of HER2-positive breast cancers}

The patients ranged in age from 23 to 85 years (mean age, 52.62 years). All included patients were female, and the cohort was composed of 93 cases of left breast cancer and 75 cases of right breast cancer. Ninety cases of HR+/HER2+ tumors and 78 cases of HR-/HER2+ tumors were included. The clinicopathological characteristics of HER2+ breast cancers according to HR expression status are summarized in Table 1. High histological grade, high nuclear grade, and high level of TILs were significantly associated with HR-negative cases ( $p<0.001$ for all comparisons).

\section{Expression of MxA protein in HER2-positive breast can- cers}

We analyzed MxA protein expression in breast tissue by immunohistochemistry. In HER2-positive breast cancers, tumor cells only showed MxA protein expression in the cytoplasm. Correlations between clinicopathological factors and MxA expression levels are shown in Table 2. High expression of MxA protein was significantly associated with high histological grade $(\mathrm{p}=0.023)$ and high level of TILs $(\mathrm{p}=0.002)$. 


\section{Prognostic significance of TILs and MxA protein expres- sion}

The level of TILs was divided into three categories (0\%-10\%, 20\%-60\%, and $>60 \%)$ for comparisons with various histopathologic parameters (Table 3). The high level of TILs was significantly correlated with high histological grade $(p=0.001)$, absence of lymphovascular invasion $(p=0.007)$, absence of lymph node metastasis $(p=0.007)$, absence of HR expression ( $\mathrm{p}<0.001)$, abundant TLSs around DCIS $(\mathrm{p}=$ 0.018), and abundant TLSs around the invasive component $(\mathrm{p}<0.001)$. The level of TILs was divided into two groups $(\leq 60 \%$ and $>60 \%)$ for survival analysis. A high level of TILs was associated with better disease-free survival in total HER2-positive breast cancers $(\mathrm{p}=0.028)$ and particularly in HR-/ HER2+ breast cancers ( $p=0.019)$ (Fig. 3). However, the expression level of MxA was not a prognostic factor (data not shown).

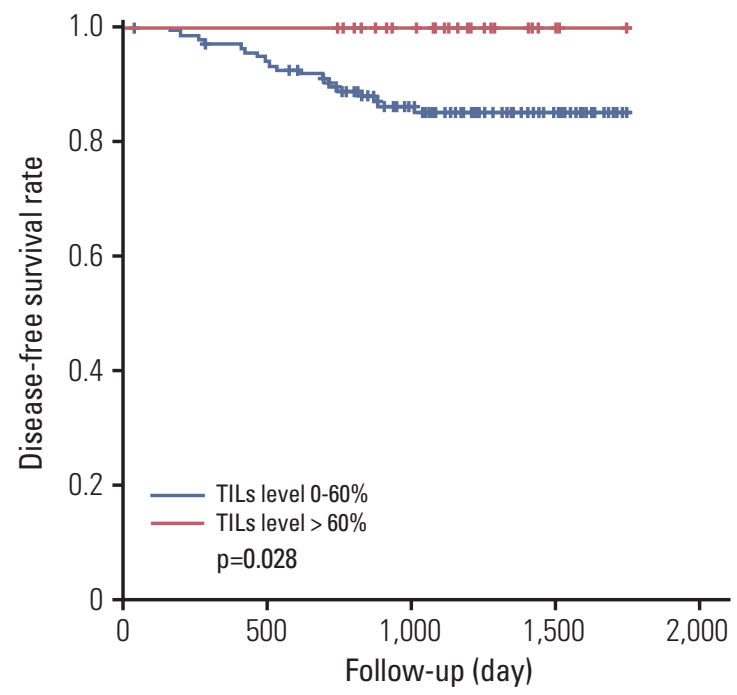

A
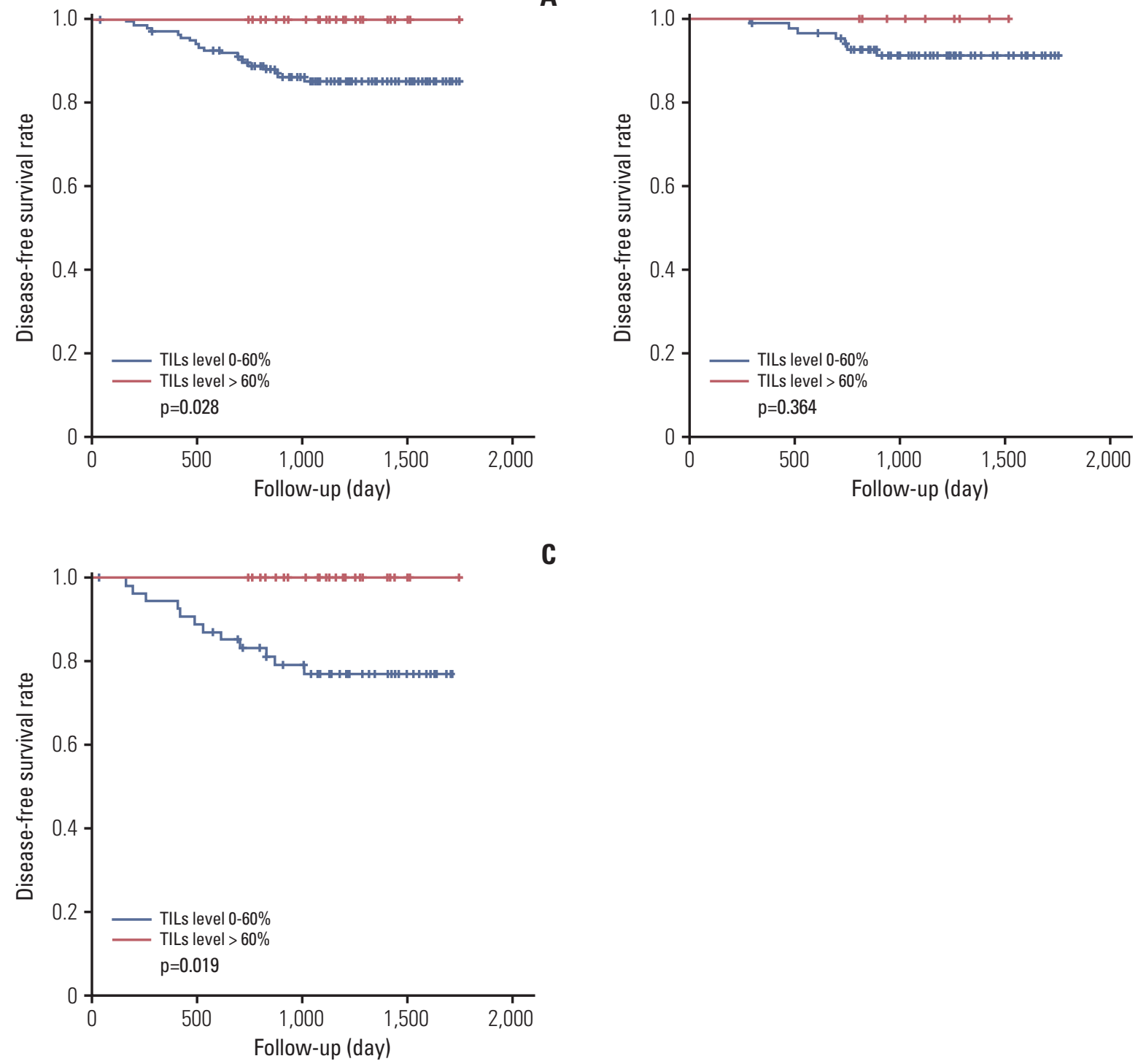

C

Fig. 3. Relationship between tumor infiltrating lymphocytes (TILs) level and disease-free survival in total human epidermal growth factor receptor 2 (HER2)-positive breast cancers (A), hormone receptor (HR)+/HER2+ breast cancers (B), and HR/HER2+ breast cancers (C). 


\section{Discussion}

IFN genes are transcriptionally silent under normal conditions. Production of IFNs is transient and triggered with stimulation by pathogen-associated molecular patterns, which are conserved among microbial species, and by DAMPs, which are endogenous molecules released from damaged or injured cells $[10,12]$. IFNs directly affect T-cell activation as a signal 3 cytokine, which is a specific cytokine signal involved in differentiation of naïve $\mathrm{T}$ cells into effector and memory T cells [13]. Additionally, type I IFN can affect $\mathrm{T}$-cell activation indirectly through mediation of the differentiation of monocytes into mature dendritic cells, which are important antigen-presenting cells, and enhancement of antigen presentation by major histocompatibility (MHC) class II synthesis and antigen processing [14]. However, IFNs have both immunostimulatory and immunosuppressive effects in cancers. Type I IFNs can elevate the expression of tumor programmed cell death ligand 1 (PD-L1), and the IFN-driven elevation of PD-L1 is thought to interact with programmed death 1 on T cells, resulting in T-cell exhaustion [15]. Moreover, one report demonstrated that high expression of ISGs is associated with poor response to therapy and immune suppression [6].

Expression of MxA in cancer has been reported in various types of organs. In head and neck squamous cell carcinoma, hypermethylation of MxA was observed relative to lymphocytes from healthy individuals [16]. In the human prostate carcinoma cell line, transfection of MxA inhibited tumor cell motility [17]. Brown et al. [18] revealed that silencing of MxA expression enhances cell migration, invasion, and anchorage independent growth, which are the hallmarks of an aggressive tumor. Quantitative proteome profiling showed that MxA has a potential role as a marker for lymph node metastasis in colorectal cancer [19]. MxA expression has been reported to be upregulated in cell line and xenograft models of HR-positive breast cancer with anti-estrogen resistance $[20,21]$. Additionally, Johansson et al. [22] showed that MxA expression was higher in a relapse group than in controls, but that it was not correlated with relapse-free survival and breast cancer-specific survival in ER-positive breast cancer treated with adjuvant tamoxifen. Conversely, Sistigu et al. [23] showed that MxA expression is positively associated with tumor grade, and that the type I IFN metagene centered around MxA can function as a biomarker for pathologic complete response to neoadjuvant anthracycline-based chemotherapy in breast cancer. Moreover, MxA expression predicts metastasis-free survival after adjuvant chemotherapy in the subset of patients of breast cancer with poor prognosis [23]. This study revealed the prognostic value of TILs in HER2positive breast cancer and the correlation between MxA expression and TIL level. However, we also found that MxA expression could not predict prognosis. It should be noted that this study had several limitations, including a relatively small cohort and a short follow-up period, which may not have been sufficient to draw conclusive results. Furthermore, multiple cell types in the tumor microenvironment can show high expression of ISGs and affect the therapeutic response in breast cancer [24]. In this study, we only evaluated MxA expression in tumor cells due to constraints with tissue microarray sections. Overall, further studies of the effects of IFN signaling on tumor immunology in breast cancer are required to better elucidate the mechanism of TILs and develop immunotherapies.

The prognostic value of TIL evaluation with H\&E sections was assumed in this study, supporting the recommendations by an International TILs Working Group 2014 [4]. Several reports have indirectly supported the hypothesis that peripheral blood T and B lymphocytes are marshaled to TLSs and that differentiated cells migrate to the tumor, where they develop into TILs $[3,25,26]$. In this study, we showed that a high level of TILs was significantly associated with the abundance of TLSs around both the invasive component and DCIS, which also indirectly supported the above hypothesis.

There are at least two subtypes of HER2-positive breast cancers according to the Cancer Genome Atlas Network [27], the HER2-enriched mRNA subtype and luminal mRNA subtype. Moreover, different clinical behaviors and histopathologic characteristics of HR+/HER2+ breast cancers and HR-/HER2+ breast cancers have been reported $[28,29]$. In this study, we found that HR-/HER2+ breast cancers were significantly associated with a higher histologic grade, higher nuclear grade, and abundant amount of TILs when compared to HR+/HER2+ breast cancers, consistent with previous studies.

\section{Conclusion}

In summary, evaluation of TILs with H\&E section can provide prognostic information in routine practice. Moreover, high expression of MxA in tumor cells was associated with a high level of TILs in HER2-positive breast cancers and a high level of TILs was a prognostic factor for breast cancer. However, the level of MxA expression had no prognostic value.

\section{Conflicts of Interest}

Conflict of interest relevant to this article was not reported. 


\section{References}

1. Ahn SG, Jeong J, Hong S, Jung WH. Current issues and clinical evidence in tumor-infiltrating lymphocytes in breast cancer. J Pathol Transl Med. 2015;49:355-63.

2. Stagg J, Loi S, Divisekera U, Ngiow SF, Duret H, Yagita H, et al. Anti-ErbB-2 mAb therapy requires type I and II interferons and synergizes with anti-PD-1 or anti-CD137 mAb therapy. Proc Natl Acad Sci U S A. 2011;108:7142-7.

3. Lee HJ, Kim JY, Park IA, Song IH, Yu JH, Ahn JH, et al. Prognostic significance of tumor-infiltrating lymphocytes and the tertiary lymphoid structures in HER2-positive breast cancer treated with adjuvant trastuzumab. Am J Clin Pathol. 2015; 144:278-88.

4. Salgado R, Denkert C, Demaria S, Sirtaine N, Klauschen F, Pruneri $G$, et al. The evaluation of tumor-infiltrating lymphocytes (TILs) in breast cancer: recommendations by an International TILs Working Group 2014. Ann Oncol. 2015;26:259-71.

5. Schlee M. Master sensors of pathogenic RNA: RIG-I like receptors. Immunobiology. 2013;218:1322-35.

6. Weichselbaum RR, Ishwaran H, Yoon T, Nuyten DS, Baker SW, Khodarev N, et al. An interferon-related gene signature for DNA damage resistance is a predictive marker for chemotherapy and radiation for breast cancer. Proc Natl Acad Sci U S A. 2008;105:18490-5.

7. Laplante M, Sabatini DM. mTOR signaling in growth control and disease. Cell. 2012;149:274-93.

8. Hu JL, Hua YJ, Chen Y, Yu B, Gao S. Structural analysis of tumor-related single amino acid mutations in human MxA protein. Chin J Cancer. 2015;34:583-93.

9. Haller O, Staeheli P, Schwemmle M, Kochs G. Mx GTPases: dynamin-like antiviral machines of innate immunity. Trends Microbiol. 2015;23:154-63.

10. Takeuchi O, Akira S. Pattern recognition receptors and inflammation. Cell. 2010;140:805-20.

11. Lee HJ, Kim JY, Song IH, Park IA, Yu JH, Ahn JH, et al. High mobility group B1 and N1 (HMGB1 and HMGN1) are associated with tumor-infiltrating lymphocytes in HER2-positive breast cancers. Virchows Arch. 2015;467:701-9.

12. Borden EC, Sen GC, Uze G, Silverman RH, Ransohoff RM, Foster GR, et al. Interferons at age 50: past, current and future impact on biomedicine. Nat Rev Drug Discov. 2007;6:975-90.

13. Crouse J, Kalinke U, Oxenius A. Regulation of antiviral T cell responses by type I interferons. Nat Rev Immunol. 2015;15: $231-42$.

14. Simmons DP, Wearsch PA, Canaday DH, Meyerson HJ, Liu YC, Wang Y, et al. Type I IFN drives a distinctive dendritic cell maturation phenotype that allows continued class II MHC synthesis and antigen processing. J Immunol. 2012;188:311626.

15. Minn AJ. Interferons and the immunogenic effects of cancer therapy. Trends Immunol. 2015;36:725-37.

16. Calmon MF, Rodrigues RV, Kaneto CM, Moura RP, Silva SD, Mota LD, et al. Epigenetic silencing of CRABP2 and MX1 in head and neck tumors. Neoplasia. 2009;11:1329-39.

17. Mushinski JF, Nguyen P, Stevens LM, Khanna C, Lee S, Chung
EJ, et al. Inhibition of tumor cell motility by the interferoninducible GTPase MxA. J Biol Chem. 2009;284:15206-14.

18. Brown SG, Knowell AE, Hunt A, Patel D, Bhosle S, Chaudhary $\mathrm{J}$. Interferon inducible antiviral $\mathrm{MxA}$ is inversely associated with prostate cancer and regulates cell cycle, invasion and docetaxel induced apoptosis. Prostate. 2015;75:266-79.

19. Croner RS, Sturzl M, Rau TT, Metodieva G, Geppert CI, Naschberger E, et al. Quantitative proteome profiling of lymph node-positive vs. -negative colorectal carcinomas pinpoints MX1 as a marker for lymph node metastasis. Int J Cancer. 2014;135:2878-86.

20. Huber M, Bahr I, Kratzschmar JR, Becker A, Muller EC, Donner $\mathrm{P}$, et al. Comparison of proteomic and genomic analyses of the human breast cancer cell line T47D and the antiestrogen-resistant derivative T47D-r. Mol Cell Proteomics. 2004;3: 43-55.

21. Becker M, Sommer A, Kratzschmar JR, Seidel H, Pohlenz HD, Fichtner I. Distinct gene expression patterns in a tamoxifensensitive human mammary carcinoma xenograft and its tamoxifen-resistant subline MaCa 3366/TAM. Mol Cancer Ther. 2005;4:151-68.

22. Johansson HJ, Sanchez BC, Forshed J, Stal O, Fohlin H, Lewensohn R, et al. Proteomics profiling identify CAPS as a potential predictive marker of tamoxifen resistance in estrogen receptor positive breast cancer. Clin Proteomics. 2015;12:8.

23. Sistigu A, Yamazaki T, Vacchelli E, Chaba K, Enot DP, Adam J, et al. Cancer cell-autonomous contribution of type I interferon signaling to the efficacy of chemotherapy. Nat Med. 2014;20:1301-9.

24. Farmer P, Bonnefoi H, Anderle P, Cameron D, Wirapati P, Becette $\mathrm{V}$, et al. A stroma-related gene signature predicts resistance to neoadjuvant chemotherapy in breast cancer. Nat Med. 2009;15:68-74.

25. Goc J, Germain C, Vo-Bourgais TK, Lupo A, Klein C, Knockaert $S$, et al. Dendritic cells in tumor-associated tertiary lymphoid structures signal a Th1 cytotoxic immune contexture and license the positive prognostic value of infiltrating CD8+ T cells. Cancer Res. 2014;74:705-15.

26. Martinet L, Garrido I, Filleron T, Le Guellec S, Bellard E, Fournie JJ, et al. Human solid tumors contain high endothelial venules: association with $\mathrm{T}$ - and B-lymphocyte infiltration and favorable prognosis in breast cancer. Cancer Res. 2011;71:567887.

27. Cancer Genome Atlas Network. Comprehensive molecular portraits of human breast tumours. Nature. 2012;490:61-70.

28. Harvey JM, Clark GM, Osborne CK, Allred DC. Estrogen receptor status by immunohistochemistry is superior to the ligand-binding assay for predicting response to adjuvant endocrine therapy in breast cancer. J Clin Oncol. 1999;17:147481.

29. Lee HJ, Park IA, Park SY, Seo AN, Lim B, Chai Y, et al. Two histopathologically different diseases: hormone receptor-positive and hormone receptor-negative tumors in HER2-positive breast cancer. Breast Cancer Res Treat. 2014;145:615-23. 